\title{
O PROCESSO DE GESTÃO DA MARCA “VINHO DO PORTO": RELEVÂNCIA DA MARCA-PAÍS E DOS AGLOMERADOS PRODUTIVOS
}

\author{
Caio Miralles de Araújo' \\ Luís Moretto Neto ${ }^{2}$ \\ Valentina Gomes Haensel Schmitt ${ }^{3}$
}

\begin{abstract}
Resumo
No mundo dos negócios é incontestável o valor das marcas, relacionando-se muito estreitamente com os objetivos organizacionais e implementação de estratégias de negócio. Este artigo tem como objetivo analisar características inerentes à gestão da marca "Vinho do Porto", destacando a perspectiva da "marca-país" e relevância da gestão desta como vantagem competitiva, para o produto e país de modo geral. A coleta de dados baseou-se na observação - durante período de vivência em Portugal por um dos autores -, informações levantadas em institutos relacionados ao Vinho do Porto, empresas comerciantes, e obras publicadas sobre o Vinho. A análise baseou-se em referencial relacionado à gestão de marcas, publicidade, posicionamento e clusters. Destacam-se os esforços das empresas na divulgação da marca no mercado global, institutos envolvidos e até mesmo do governo, por se tratar de um produto não só gerador de muitos empregos diretos e indiretos, mas um embaixador português mundialmente.
\end{abstract}

Palavras-chave: Vinho do Porto. Marca. Marca-país

\section{INTRODUÇÃO}

O Vinho do Porto é um vinho licoroso, produzido na Região Demarcada do Douro. Situada no nordeste de Portugal, na bacia hidrográfica do Douro, a região

\footnotetext{
'Bacharel em Ciências da Administração pela Universidade Federal de Santa Catarina - UFSC. Universidade Federal de Santa Catarina, Centro Sócio-Econômico, Departamento de Ciências da Administração. Campus Universitário s/n, Trindade, Florianópolis, SC. CEP: 88040-900.E-mail: caiomiralles@yahoo.com.br.

${ }^{2}$ Doutor em Engenharia de Produção pela Universidade Federal de Santa Catarina - UFSC. Professor Associado do Departamento de Ciências da Administração da Universidade Federal de Santa Catarina - UFSC. Av. Rubens de Arruda Ramos, I540 apto I02, Centro, Florianópolis, SC. CEP: 880 I5-700. E-mail: moretto@cse.ufsc.br.

${ }_{3}^{3}$ Mestre em Ciências da Administração pela Universidade Federal de Santa Catarina - UFSC. Professora Substituta Departamento de Ciências da Administração da Universidade Federal de Santa Catarina - UFSC. Rua Beija Flor, 37, Lagoa da Conceição, Florianópolis, SC. CEP: 88062-253 E-mail: valentinaschmitt@hotmail.com Artigo recebido em: 10/10/2007. Aceito em: 26/04/2008. Membro do Corpo Editorial Científico responsável pelo processo editorial: Prof. Gilberto de Oliveira Moritz
} 
apresenta características mesológicas e climáticas particulares. A região demarcada do Douro estende-se rio acima, aproximadamente 100 quilômetros a leste do Porto, até a fronteira com a Espanha, e é a região vinícola demarcada mais antiga do mundo, reconhecida, desde 2001, como Patrimônio Mundial pela Organização das Nações Unidas para a Educação, a Ciência e a Cultura (UNESCO).

O início da história do Vinho do Porto se dá por volta do século XVII. Rivalidades, guerras, e invasões entre os povos da Europa do norte neste período acabaram por promover os vinhos portugueses em detrimento dos mais conhecidos vinhos franceses. A partir desta época os franceses passaram a impor taxas elevadas ao vinho de Bordéus, que se exportava para a Inglaterra. Isso fez com que o Rei Carlos II decretasse o embargo à importação dos "claretes" franceses, passando então a importar quantidades apreciáveis de Vinho do Porto. Com o Tratado de Methuen (1703), também conhecido como Tratado de Panos e Vinhos, é forçado um escoamento bipartido em que Portugal passaria a comprar parte da produção inglesa de tecidos, em contrapartida para as exportações de vinho (LOPES, 1996).

As empresas que produzem o Vinho do Porto são quase que na totalidade centenárias, e são resultado de todos os fatores históricos que moldaram a realidade do mercado e do produto. Isto posto, é inerente analisar como se dá a gestão da marca "Vinho do Porto", que é o objetivo deste artigo. Pretende-se destacar as principais atividades e estratégias relacionadas à marca, dando destaque à importância da "marca-país" diretamente associada ao Vinho do Porto (por ser um produto tradicional de Portugal), e aos aglomerados produtivos envolvidos no processo, que vai desde a plantação da uva até a comercialização internacional.

Segundo o Instituto dos Vinhos do Douro e do Porto (IVDP), no ano de 2006 foram vendidos 91,6 milhões de litros de Vinho do Porto, com valor total de 396 milhões de euros (4,32 euros/litro média) para os mais diversos países do mundo, em diversos continentes.

\section{METODOLOGIA}

Para a execução deste artigo, foi feito um levantamento de materiais relacionados ao Vinho do Porto em Portugal, na cidade do Porto e na vizinha Vila Nova de Gaia, que é a cidade aonde estão localizadas as empresas, e aonde o vinho é armazenado para o envelhecimento e engarrafamento. Quanto a estes dados, relativos ao Vinho do Porto, seu mercado, empresas, estrutura, houve grande dificuldade, primeiramente quanto ao acesso, visto que não há uma vasta gama de publicações a respeito do marketing das empresas, "cases" ou análises no sentido administrativo desta atividade em Portugal, mas principalmente quanto a atualidade destes dados. Muito do material que se colheu sobre o mercado e informações sobre as empresas carecia de atualizações. 
Os dados primários foram levantados a partir de observação do autor ao mercado e visitas às empresas durante o período de seis meses em que esteve na região do Porto, durante o período compreendido entre março e junho de 2006. Poucas foram as informações conseguidas através de entrevista realizada no Instituto dos Vinhos do Porto e do Douro (IVDP), em Portugal. Lá, conseguiu-se bastante acesso a materiais impressos e publicamente já conhecidos, sendo que as informações divulgadas por entrevista semiestruturada realizada pessoalmente com um dos funcionários do marketing forneciam somente as mesmas informações publicadas, sem maior profundidade.

Os levantamentos em dados secundários não relativos ao vinho foram realizados notadamente em livros especializados sobre marketing, gestão de marcas e clusters, e apresentou-se bastante acessível, dada a quantidade e qualidade de publicações sobre o assunto, dentro das mais diversas vertentes.

A abordagem metodológica utilizada aqui neste artigo pode ser classificada como qualitativa, por identificar a presença ou ausência de algo, que é no caso a gestão da marca "Vinho do Porto", e a presença ou não de atividades e estratégias relacionadas a ela. Também procurou-se unicamente entender as questões relacionadas à marca "Vinho do Porto", expondo suas peculiaridades, não respondendo ou analisando a causa de determinados fatos, podendo ser considerada, portanto, uma pesquisa descritiva.

A pesquisa empreendida se caracteriza como um estudo de caso, enquanto método de trabalho, caracterizando-se pelo aprofundamento descritivo e analítico do objeto eleito. Tendo como escopo o referencial teórico e conceitos pré-definido, sendo que o caráter transitório das informações obtidas em campo impedem a generalização para outros objetos similares (BRUYNE, 1977). O estudo de caso se caracteriza como o método do pesquisador olhar para a realidade, organizando as informações relativas ao objeto eleito para análise, preservando o caráter unitário do mesmo e interpretando-o no emaranhado de inter-relações em que se encontra eleito (GOODE; HATT, 1975).

\section{DIFERENCIAÇÃO E POSICIONAMENTO DO VINHO DO PORTO}

Os consumidores consideram a marca uma parte importante do produto. Aaker (1998) afirma que para muitos negócios, o nome da marca e o que ele representa são o seu mais importante ativo, a base da vantagem competitiva e de ganhos futuros.

Para que uma marca se destaque das outras, ela precisa, acima de tudo, estar bem posicionada e diferenciada, com o intuito de não ser "mais uma". Caso alcance um bom posicionamento, terá uma atraente posição competitiva, suportada por fortes associações.

A construção e a longevidade de uma marca exigem da organização um processo de gestão apurada, na medida em que existe total interdependência entre a valorização 
da marca, por parte dos mercados e, com a rentabilidade econômico-financeira das organizações. A cada ano, os principais veículos econômicos dos paises desenvolvem estudos e estabelecem ranking de posicionamento de marcas, elementos decisivos na avaliação financeira da organização, inclusive no mercado econômico. No Brasil, veículos de comunicação e entidades associativas, relacionadas ao desenvolvimento de estudos e pesquisas mercadológicas, realizam de maneira sistemática a avaliação das marcas, e a publicação de indicadores, com destaques para o ranking do Jornal Valor Econômico, "Marcas de Confiança" de seleções em parceria com o Instituto Brasileiro de Pesquisa e Estatística (IBOPE), bem como o "Top of Mind" do Jornal Folha de São Paulo e DataFolha com o histórico de dezesseis anos (MADIA, 2008).

O gerenciamento da marca demanda um esforço continuado, no estabelecimento de relações sinérgicas com fornecedores e canais de distribuição, de modo a garantir que os insumos tangíveis e intangíveis agregados por estes ao resultado do produto possam incrementar a percepção do consumidor em relação às suas expectativas iniciais. Numa organização de serviços a abordagem gerencial das marcas tem seu foco no capital humano, ao passo que em uma organização industrial ocorre uma ampliação da complexidade, na medida em que insumos materiais e tecnologias de produção, bem como embalagens e rotulagens demandarão um esforço maior do gestor para preservar os elementos distintivos da marca (GUIMARÃES, 2003).

Para Kotler e Armstrong (1998, p.174), a posição de um produto é a forma como o produto é definido pelos consumidores quanto a seus atributos mais importantes - é o lugar que ele ocupa na cabeça dos consumidores com relação aos produtos concorrentes.

Por se tratar de uma denominação de origem, a marca "Vinho do Porto" já traz consigo um posicionamento natural e único, possuindo nome diferenciado e a identificação imediata do produto pelo consumidor. Esta associação se dá, a princípio, pela designação geográfica. Ela vem do tempo em que o produto tinha como destino principal o mercado inglês, ou seja, há mais de 300 anos.

As marcas existem para identificar e representar produtos e empresas, cumprem uma função simbólica, criando significados para o consumidor, bem como identidade estando relacionadas à experiências vividas por estes no momento do consumo. A identidade da marca está relacionada à três dimensões, no nível axiológico - que resgata a essência dos valores -, ao nível narrativo - papeis e relatos das experiências - e ao nível de superfície - relacionado a atores e objetos reais. No mercado, o consumidor relaciona ou avalia a marca, preferencialmente, ao nível de superfície (SERAGINI; GUARDADO, 2003).

O que torna o Vinho do Porto diferente dos demais vinhos é o fato de a fermentação do vinho não ser completa, sendo parada numa fase inicial (dois ou três dias depois do início), através da adição de uma aguardente vínica neutra (com cerca de 
$77^{\circ}$ de álcool). Assim o vinho do Porto é um vinho naturalmente doce (visto o açúcar natural das uvas não se transformar completamente em álcool) e mais forte que os demais vinhos (entre 18 e 22 graus de álcool).

Aaker (1998) afirma que em algumas classes de produtos, como vinhos, perfumes e roupas, as várias marcas não são distintas para a maioria dos consumidores. As associações do nome da marca podem, então, desempenhar um papel crítico na separação de uma marca da outra. Uma associação diferenciadora pode ser uma vantagem competitiva chave, como é o caso do Vinho do Porto frente aos vinhos de outras partes do mundo.

Além da designação geográfica, um atributo que lhe agrega valor não é gerenciado ou não se trata de uma ação planejada. O fato da marca "Vinho do Porto" ser somente usada pelo vinho produzido naquela região, trás consigo a idéia de exclusividade, de um produto único, especial, e esta associação é bastante positiva na mente do consumidor. Além disso, existem categorias de vinhos que requerem longos anos de maturação, como é o caso dos Tawnys envelhecidos, Data de Colheita ou Vintage. Estes são produtos raríssimos e de grande qualidade, vendidos muitas vezes através de leilão, que conferem valor ainda maior às marcas que os comercializam, paralelamente associados também aos vinhos mais simples na mente do consumidor. Entre as classes mais abastadas da Inglaterra, saber distinguir um Vintage de outro era um sinal de requinte e de refinamento no passado, tal o status associado a este tipo de produto.

Outro ponto importante, principalmente no ramo alimentício, é o da escolha e formatação adequada do rótulo e embalagem. Os rótulos podem desempenhar várias funções, e os vendedores devem decidir quais dessas serão ativadas. No mínimo, o rótulo identifica o produto ou a marca, mas pode também classificar o produto ou descrever várias coisas sobre ele - quem o fabricou, onde e quando foi fabricado, qual é o seu conteúdo, como deve ser usado, e como usa-lo com segurança. No que tange ao Vinho do Porto, é bastante comum as logomarcas e as imagens contidas nas garrafas representarem navios, rosas dos ventos, a Cruz de Malta, imagens que remetam ao passado português da época das navegações ou propriamente à história do vinho. São comumente encontradas também imagens que remetem à Inglaterra, mercado histórico do vinho e de onde advém muitas das famílias fundadoras das empresas, que levam o nome inglês até hoje. Estas empresas encontram maior facilidade em adentrar o mercado britânico devido a esta simples alusão. Mesmo não sendo de origem inglesa, algumas empresas de outras nacionalidades também carregam escudos, coroas e leões em suas logomarcas (o leão é historicamente um símbolo inglês).

Destaca-se ainda, quanto à diferenciação e posicionamento da marca, o controle rígido de qualidade pelo qual passa o produto antes de atingir o mercado. Afinal, não há como ter uma marca forte sem um produto com qualidade assegurada. Para isso, o IVDP tem investido nos últimos anos nas mais avançadas técnicas de análise, realizando 
O processo de gestão da marca "Vinho do Porto": relevância da marca-país e dos aglomerados produtivos

constantes verificações das características dos vinhos, controle analítico e de prova de todos os lotes de aguardente vínica destinada à produção de Vinho do Porto.

Sendo o produto aprovado em todos os processos analíticos, ele passa então a exibir, na garrafa, um lacre de garantia assegurada pelo IVDP, contendo o número do lote de teste do mesmo, que é a garantia de qualidade do produto, assim como que legitima o produto como um verdadeiro Vinho do Porto.

\section{A "MARCA-PAÍS" E O VINHO DO PORTO}

A partir do século XV, o desenvolvimento do comercio mundial fez com que os vendedores começassem a indicar os locais de origem da mercadoria, agregando valor a esta. Era causador de frisson relatar que as especiarias vinham da Índia, a madeira do Brasil e as sedas do Japão. Tanto os locais de origem como a divulgação de seus fabricantes/comerciantes forneciam ao consumidor do passado uma referência de origem e uma proposta conhecida de qualidade, suficiente para as exigências de então. Algumas dessas marcas sobrevivem até hoje exatamente com o nome com que foram criadas, séculos atrás (DIAS, 2002). Uma dessas marcas é o Vinho do Porto.

Um país pode ser um símbolo forte, desde que tenha uma ligação próxima com os produtos, materiais e capacitação. Assim, a Alemanha é associada com cervejas e automóveis de categoria, a Itália, com sapatos e artigos de couro, e a França, como moda e perfumes. Essas associações podem ser exploradas pela referência de uma marca com o país (AAKER, 1998). Naturalmente, se associa o Vinho do Porto à Portugal. Logotipos, rótulos, imagens correlatas ao produto, remetem sempre à sua tradição e história, promovendo o produto como uma espécie de mala diplomática, um verdadeiro embaixador de Portugal no mundo. Veiculam um certo conceito de portugalidade, "exportando" mais que um produto, uma cultura e o seu patrimônio.

T.A. Shimp, S. Saeed e T.J Madden (apud KOTLER; GERTNER, 2004) utilizaram, em 1993, a expressão "country equity" (valor da marca país) para descrever o valor emocional resultante das idéias que os consumidores associam com o país. Isso acontece quando o nome de um país os ajuda a avaliar os produtos provenientes dali e a tomar suas decisões de compra.

Bastante associado a estes fatores está os constantes esforços na área turística. Conforme cita Kotler e Gertner (2004, p. 215), "o turismo requer estratégias de imagem e marca fundamentadas na realidade do lugar". Relatam que, segundo levantamento da Organização Mundial do Turismo, na década de 90, o número de turistas internacionais cresceu a um ritmo médio de 4,3\% ao ano. Em 2000, o turismo internacional aumentou 7,4\%, a quantidade de turistas internacionais chegou a 699 milhões e as viagens e o turismo foram responsáveis, diretas e indiretamente, por $11,7 \%$ do Produto Interno Bruto mundial e por cerca de 200 milhões de empregos. 
Portugal tem, a cada ano, recebido mais turistas, em grande parte relacionada a entrada na Comunidade Européia. No primeiro trimestre de 2007, foram $8,5 \%$ de crescimento, sendo que 7,5\% da população ativa está empregada neste setor (VIEIRA, 2007).

As empresas de Vinho do Porto, independentemente, promovem dois tipos de atividade. A primeira delas é a visita às caves do Vinho do Porto, que estão majoritariamente localizadas às margens do rio Douro em Vila Nova de Gaia, ao lado da cidade do Porto. Lá, realizam um passeio guiado por onde fica armazenado o vinho, conhecendo a estrutura da empresa, as pipas, como é armazenado e vislumbram através do guia da empresa a história do vinho e da mesma. Por fim, realiza-se provas dos vinhos, podendo o visitante comprar o produto que desejar, que vai desde vinhos, a lembranças como cartões postais, chaveiros, souvenires em geral.

A segunda atividade é a visita às Quintas localizadas no interior do país. Nele, o turista pode conhecer as vinhas, e ver o processo de produção do vinho. Algumas vezes, é possível assistir, e se preferir participar, do processo de pisa tradicional das uvas, realizado até hoje por muitas das empresas.

Todas estas atividades turísticas têm como intuito gerar uma associação da história e tradição com a marca "Vinho do Porto" na mente dos visitantes, tendo estas ações apelo muito mais forte e duradouro que uma simples campanha publicitária. Por mais simples que seja o passeio, ele estará por muito tempo na mente do visitante, associado ao vinho e às experiências lá vividas, devida utilização de todos os sentidos sensoriais do visitante, notadamente os olfativos, gustativos e visuais. Conforme Brizante (2005, p.37) relata, "quanto maior o número de sensores impactados por uma informação, mais fácil será sua recuperação no dia-a-dia, mais fácil lembrar de determinado produto na hora da compra”.

Estas são estratégias de imagem e marca fundamentadas na realidade do lugar, ou seja, orientadas ao Vinho do Porto, que faz parte da história do local em todos os sentidos, em suas ruas, avenidas, prédios e toda a economia da região.

Utilizando-se de uma outra abordagem, com os mesmos objetivos, o Instituto dos Vinhos do Douro e do Porto (IVDP) vem investindo e promovendo ao redor do mundo encontros, feiras vinícolas, alimentícias, ações conjuntas a restaurantes e redes hoteleiras. Desta forma, associa as mais diversas opções alimentícias à um estilo determinado de Vinho do Porto, e tem passado esta sugestão aos chefes de restaurantes e sommeliers, que acabam por disponibilizar e sugerir o Vinho do Porto aos clientes, numa inteligente promoção do produto.

\section{OS AGLOMERADOS PRODUTIVOS DO VINHO DO PORTO}

Conforme já relacionado, países usam o próprio nome para promover seus produtos. Assim é o Vinho do Porto para Portugal. Para que se ocorra esta associação, 
é preciso mais que esforços na área de marketing. Um dos determinantes mais importantes e amplos para esta condição é a presença, no país, de indústrias correlatas que sejam internacionalmente competitivas.

As indústrias correlatas, ou clusters, são aquelas nas quais as empresas, ao competir, podem coordenar ou partilhar atividades na cadeia de valores, ou aquelas que envolvem produtos complementares, como é o caso do Vinho do Porto, em que um grande número de empresas e produtores participa das etapas do processo produtivo, seja no cultivo da uva, que é cultivada por cerca de 30 mil viticultores, onde se desenvolvem técnicas de maior produtividade, enxertos e melhores operações culturais, comumente compartilhadas, até a produção e venda do vinho, em que atuam também diversas empresas que compartilham processos tecnológicos e de distribuição. Uma das características do setor é a existência de relações estáveis e duradouras entre os muitos viticultores e firmas exportadoras. Não é difícil encontrar casos de uma mesma família de lavradores vendendo a sua produção para a mesma empresa durante gerações.

Porter (1989), um dos autores centrais sobre o tema, afirma que nações com posições de liderança mundial têm, em muitos casos, vários rivais locais fortes, até mesmo em países pequenos como Suíça ou Suécia. Esses exemplos desmentem a idéia simples de que a liderança mundial advém de uma ou duas firmas que colhem economias de escala no mercado interno.

Recentemente, o mercado de Vinho do Porto passou por um grande processo de fusões e aquisições de empresas, que culminou numa maior concentração na mão de poucos grupos, num setor que era, anteriormente, bastante diluído. Mesmo com este maior domínio dos grandes grupos hoje em dia, a prática demonstra que as empresas pequenas, quando concorrendo de forma não predatória, podem ainda conseguir vantagens competitivas duráveis. Na competição global, as empresas bemsucedidas competem vigorosamente em seu país e pressionam-se mutuamente para melhorar e inovar, como é o caso do Vinho do Porto. Isto também se deve ao fato de estarem todas localizadas no mesmo local, no caso das empresas comerciantes, em Vila Nova de Gaia. Esta proximidade propicia a troca natural de informações, e a participação conjunta em atividades.

Um grupo de rivais locais tenta abordagens alternativas da estratégia e cria uma gama de produtos e serviços que cobre muitos segmentos. Algumas empresas se mobilizam na produção de vinhos de qualidade, outros concorrem com relação à preço, e existem ainda os que utilizam táticas inovadoras, oferecendo, por exemplo, uma embalagem mais moderna, outras oferecem embalagens com menor capacidade, e outras ainda apostam na diferenciação oferecendo uma gama de produtos mais secos e suaves, voltado ao público feminino e à produção de coquetéis. 
Isso propicia inovação, a amplitude de produtos e abordagens, além de levantar defesas contra concorrentes ou substitutos. O estoque de conhecimento e capacidade na indústria de um país se acumula à medida que as firmas se imitam e o pessoal se movimenta entre elas (PORTER, 1989).

Por volta de 1992, o então primeiro ministro de Portugal Cavaco Silva (atual presidente do país), contratou o economista Michael Porter, para desenvolver um estudo sobre Portugal. O desafio, as ameaças e as oportunidades postas pela globalização, produziu um relatório da Monitor Company intitulado "Construir as Vantagens Competitivas de Portugal”, apresentado em 1994. Michael Porter identificava na altura um conjunto de "clusters" que Portugal deveria apostar para crescer. Concluído o estudo, Porter identificou os produtos tradicionais portugueses, como o vinho, o turismo, a madeira, a cortiça e algum vestuário como os "clusters" que Portugal deveria implementar (PORTUGALNEWS, 2007).

Foram apresentados dois relatórios pelo "Monitor Group”, consultora de Michael Porter. O primeiro, entitulado "Relatório Porter I: qualidade para os mercados externos" analisa o cluster do vinho português e considera que a oferta de vinhos de qualidade de Portugal é, atualmente, abundante e diversificada. No segundo, "Relatório Porter II: estratégias para os mercados norte-americano e britânico", Michael Porter aponta estes países como mercados de aposta, dado que são os dois maiores importadores de vinho a nível mundial, que poderão projetar a imagem e as exportações nacionais de vinhos. O Monitor Group vem desde então desenvolvendo ações e estratégias não só para as empresas de Vinho do Porto, mas para as empresas vinícolas como um todo em Portugal, criando propriamente uma marca com relação a seus vinhos associada a qualidade.

Sobre estes relatórios, em que se relaciona também a perspectiva da especialização, e os mercados atendidos pelo Vinho do Porto, deve-se relatar os atuais esforços em fortalecer-se nos mercados dos Estados Unidos e do Reino Unido, deliberadamente descritos como mercados prioritários. Relata que "o cluster dos vinhos de Portugal decidiu reforçar a concentração na exportação, juntamente com uma série de iniciativas para melhorar a sua competitividade" (MONITOR GROUP, 2004). Esta é a principal estratégia de âmbito governamental relacionada ao Vinho do Porto e a todos os outros tipos de vinhos produzidos no país (vinhos de mesa).

Ao analisar as metas e o plano traçado para o alcance destas metas, percebese que buscam apenas o fortalecimento da marca-país "Portugal" e seus produtos. Os vinhos portugueses muitas vezes ocupam a categoria de vinhos espanhóis, ou são classificados como "Resto do Mundo", ou "Não-Classificado", o que do ponto de vista da marcas é muito ruim, pois não cria identidade e imagem própria, não posiciona e não diferencia. $\mathrm{O}$ estabelecimento de uma categoria própria funciona como um pólo de atração para os consumidores. 
O processo de gestão da marca "Vinho do Porto": relevância da marca-país e dos aglomerados produtivos

\section{CONSIDERAÇÕES FINAIS}

Através deste artigo, pode-se conhecer um pouco mais sobre o Vinho do Porto, um produto caracteristicamente português. A contextualização do seu percurso passado em paralelo com a atualidade permite vislumbrar que sua marca é a muito tempo voltada para os mercados internacionais, e esforços neste sentido vêm sendo tomados ao longo dos anos. Se no passado a idéia da marca passava pela adaptação ao mercado consumidor do país importador, hoje percebe-se que este consumidor começa a manifestar interesse pelo produto "diferente" e valorizar aqueles que trazem consigo uma identidade. Portanto, mais do que nunca, é necessário se destacar esta identidade única, esta autenticidade do produto tipicamente português, como fator valorizador do produto, bem posicionado e diferenciado. Algo que se assemelhe à realidade do "Champagne" francês. Cabe aos gestores da marca "Vinho do Porto" criar associações únicas ao produto, como é a idéia do "glamour" do produto francês, e isto tudo passa tanto por investimentos financeiros como de maior dedicação neste sentido por parte dos envolvidos.

Pode-se aqui realizar um paralelo com a realidade brasileira, tendo sido analisado este produto tão representativo e característico de uma cultura, como é o Vinho do Porto para Portugal. Poderíamos aprender algo com relação a nossos produtos típicos observando este estudo? Produtos como a goiabada, doce de leite, rapadura, pão de queijo, poderiam ganhar o mundo, carregando uma marca? A resposta é, sem dúvida, sim.

A idéia passa, claro, por fortes investimentos, mas mais do que isso, por um gestão de marcas que carregue as características reais do produto e de toda a realidade que o cerca, buscando um posicionamento, uma identidade única e original na mente das pessoas. Temos o exemplo do Kiwi, cultivado a principio na Nova Zelândia que, através de investimentos e promoções pontuados em restaurantes sofisticados ao redor do mundo, caiu no gosto da população mundial como um misto de sofisticação e exoticidade na mente das pessoas. Frutas típicas brasileiras, como a goiaba, ou ainda como as muitas frutas típicas da região norte e nordeste do país como a graviola, açaí, pitomba, ou cupuaçu poderiam passar pelo mesmo processo. Ou melhor, que fosse agregado algum valor a eles no próprio país, como já é feito com o bombom de cupuaçu. Basta que se invista não só no processamento desta fruta, mas na criação de uma marca para seu produto.

O açaí, mesmo que timidamente, é um caso a se destacar. Depois de se tornar popular no centro-sul do país, já é exportado para alguns países, carregando o nome brasileiro como forma de estabelecer uma identidade, já sendo inclusive identificado pelo próprio autor um “Açaí Restaurant”, na região central de Londres.

Um caso até mais próximo ao Vinho do Porto é o da cachaça brasileira. Produto que não goza de uma imagem positiva dentro da grande massa da população do país, 
vem, mesmo que lentamente, conquistando cada vez mais o mercado internacional. Sua imagem, ao contrário da mentalizada por grande parte dos brasileiros, é de um produto de grande qualidade, não somente sendo utilizada na produção da "caipirinha" (drinque sempre associado à bebida), mas sendo também consumida pura. Este é um caso paralelo ao Vinho do Porto, de uma bebida típica de um país que busca espaço no mercado global, e que carrega o seu toque de "nacionalidade" e identidade características como adjetivos para seduzir o consumidor.

Outro ponto importante, e que deve ser discutido, é o do papel dos aglomerados produtivos enquanto provedores de desenvolvimento à uma economia local, conforme observado por Michael Porter (1989) em casos conhecidos, como em Modena na Itália, Baden-Wurttemberg na Alemanha, Jutland na Dinamarca. Brito (1997), na conclusão de sua obra, pergunta: se as zonas que apresentam esta característica de aglomerados produtivos no mundo, apresentam características semelhantes às encontradas no setor do Vinho do Porto, por que razão não é este setor mais um exemplo de riqueza e desenvolvimento econômico? A resposta, dada pelo próprio, afirma que em primeiro lugar a questão parece formulada como se o Vinho do Porto não fosse um caso de sucesso. Mas é. Não há muitos produtos que tenham se mantido competitivos nos mercados internacionais durante mais de três séculos. E, mais do que ser competitivo, trata-se de ser considerado um dos três grandes vinhos do mundo, a par do Bordéus e do Champanhe.

Contudo, é verdade que a região não é propriamente um modelo de desenvolvimento. $\mathrm{O}$ autor conclui sua obra dizendo que "fica apenas uma sugestão: os ingredientes existem, e há décadas ou mesmo séculos. É preciso que os atores envolvidos percebam que têm em suas mãos os mesmo elementos que fizeram de outras regiões exemplos de sucesso econômico e empresaria" (BRITO, 1997). Fica a lição para os aglomerados brasileiros.

\title{
THE BRAND MANAGEMENT OF "PORT WINE": RELEVANCE OF COUNTRY EQUITY AND OF PRODUCTIVE CLUSTERS
}

\begin{abstract}
Brand management in today's business world is extremely related to the organizations purpose and improvement of their strategies. The goal of this study is to analyze the characteristics of brand management "Port Wine", who caries a strongly distinctive name, outstanding the "country equity" and its importance in order to achieve competitive advantage, to the product and for the country in a general way. It's a study based on information obtained from institutes related to the Port Wine, commercial
\end{abstract}


O processo de gestão da marca "Vinho do Porto": relevância da marca-país e dos aglomerados produtivos

companies, and studies already publicized about the wine, being analyzed and developed with the aid of works about brand management, publicity, positioning and clusters. The structure is based on the efforts made by the company's, institutes and Portugal's government to publicize the brand upon the global market, being the product not only the creator of innumerous direct and indirect employments, but also a Portuguese ambassador to the world.

Keywords: Port Wine. Brand. Country Equity

\section{REFERENCIAS}

AAKER, David. Marcas - Brand Equity gerenciando o valor da marca. São Paulo: Negócio, 1998

BRITO, Carlos Melo. Estrutura e dinâmica do sector do vinho do Porto, Porto : Instituto do Vinho do Porto, 1997.

BRIZANTE, Samara Geraldes. Comunicação: a persuasão e os 5 sentidos, São Paulo, 2005. Disponível em: $<$ http://gestcorp.incubadora.fapesp.br/portal/monografias>. Acesso em: 11 abr. 2007.

BRUYNE, Paul de. Dinâmica da pesquisa em ciências sociais: os pólos da prática metodológica. Rio de janeiro: F. Alves, 1977.

DIAS, Emmanuel Publio. Mandato e legitimidade das marcas. Revista ESPM. São Paulo, v. 9, n.4, p. 9-19, jul/ago., 2002.

GOODE, William J.; HATT, Paul K. Métodos em pesquisa social. São Paulo: Companhia Editorial Nacional, 1975.

GUIMARÃES, Ricardo. Branding uma nova filosofia de gestão. Revista ESPM. São Paulo, v. 10, n.2, p. 84-103, mar/abr., 2003.

KOTLER, Philip; ARMSTRONG, Gary. Princípios de Marketing. 7. ed Rio de janeiro: Prentice Hall do Brasil, 1998.

; GERTNER, David. O marketing estratégico de lugares. HSM Management. ano 8, v. 3, n. 44, maio/jun., 2004. 
LOPES, Teresa da Silva. Internacionalização e concentração no Vinho do Porto, 1945-1995, uma abordagem pelos custos de transacção. GEHVID - Grupo de Estudos de História da Viticultura Duriense e do Vinho do Porto - ICEP, Investimentos, Comércio e Turismo de Portugal, 1996.

MADIA de Souza, Francisco Alberto. Marketing Trends 2008. São Paulo: Makron Books, 2008.

MONITOR GROUP. Estratégia de Marketing para vinhos portugueses na GB e nos EUA, 2004. Disponível em: <www.viniportugal.pt>. Acesso em: 15 maio 2007.

PORTER, Michael E. A vantagem competitiva das nações. 5. ed Rio de Janeiro: Campus, 1989.

PORTUGALNEWS. Estratégia do "cluster" do vinho padece de falta de estudos de mercado. Lisboa: ICEP Portugal, 2007. Disponível em: <www.portugalnews. pt>, Acesso em 10 abril 2007

SERAGINI, Lincoln; GUARDADO, Sergio. Habitat de Marca: branding brasileiro. Revista ESPM. São Paulo, v. 10, n.2, p. 84-103, mar/abr., 2003.

VIEIRA, Rui Pedro. Sócrates diz que turismo nacional atravessa "período de confiança". Consultado em 11 de maio 2007. Disponível em: <www.agenciafinanceira.iol.pt>, Acesso em 12 maio 2007. 